Published in final edited form as:

Adv Drug Deliv Rev. 2012 May 15; 64(7): 701-705. doi:10.1016/j.addr.2011.12.006.

\title{
Polymeric Nanoparticles for Drug Delivery to the Central Nervous System
}

\author{
Toral Patel ${ }^{\mathrm{a}}$, Jiangbing Zhou ${ }^{\mathrm{a}, \mathrm{b}}$, Joseph M. Piepmeiera, and W. Mark Saltzman ${ }^{\mathrm{b},{ }^{*}}$ \\ aDepartment of Neurosurgery, Yale University School of Medicine, New Haven, CT 06511 USA \\ ${ }^{b}$ Department of Biomedical Engineering, Yale University, New Haven, CT 06520, USA
}

\section{Abstract}

The central nervous system (CNS) poses a unique challenge for drug delivery. The blood-brain barrier significantly hinders the passage of systemically-delivered therapeutics and the brain extracellular matrix limits the distribution and longevity of locally-delivered agents. Polymeric nanoparticles represent a promising solution to these problems. Over the past 40 years, substantial research efforts have demonstrated that polymeric nanoparticles can be engineered for effective systemic and local delivery of therapeutics to the CNS. Moreover, many of the polymers used in nanoparticle fabrication are both biodegradable and biocompatible, thereby increasing the clinical utility of this strategy. Here, we review the major advances in the development of polymeric nanoparticles for drug delivery to the CNS.

\section{Keywords \\ nanoparticle; polymer; brain; blood-brain barrier; convection-enhanced delivery}

\section{Introduction}

Neurological disorders contribute to $6.3 \%$ of the global burden of disease and this number is projected to rise in the coming years due to an aging population [1]. Further, neurologic diseases are often associated with chronic disability, resulting in significant suffering for both the patient and their caregivers. The economic costs of these conditions are immense: in 2010, the global economic impact of dementias alone was $>\$ 600$ billion [2]. Given the substantial public health burden, significant research efforts have been directed towards the development of improved therapies for central nervous system (CNS) diseases. However, despite these efforts, treatments for CNS diseases remain limited due to the inability of therapeutic agents to adequately cross the blood-brain barrier (BBB) [3].

The BBB serves to restrict the movement of substances between the peripheral circulation and the CNS. In doing so, the BBB plays a critical role in regulating the brain microenvironment [3-6]. The BBB is formed primarily by endothelial cells that line the cerebral microvasculature and surrounding perivascular elements. Adjacent endothelial cells

(C) 2011 Elsevier B.V. All rights reserved.

*To whom correspondence should be addressed: W. Mark Saltzman, Department of Biomedical Engineering;, Yale University, P.O. Box 208284, New Haven, CT 06520, USA; Tel: (203) 432-4262; Fax: (203) 432-0030; mark.saltzman@ yale.edu.

Publisher's Disclaimer: This is a PDF file of an unedited manuscript that has been accepted for publication. As a service to our customers we are providing this early version of the manuscript. The manuscript will undergo copyediting, typesetting, and review of the resulting proof before it is published in its final citable form. Please note that during the production process errors may be discovered which could affect the content, and all legal disclaimers that apply to the journal pertain. 
form complex tight junctions with substantial transendothelial electrical resistance (TEER), creating a physical barrier which severely limits paracellular transport across the BBB. This is in stark contrast to the peripheral circulation, which exhibits a low TEER and efficient paracellular transport. In addition to the physical barrier created by the tight junctions, the BBB also contains several metabolic barriers to drug delivery. Specifically, the endothelial cells of the BBB are designed to allow minimal pinocytosis, thereby largely eliminating nonspecific transcellular trafficking. Additionally, each of the cellular constituents of the BBB expresses an array of intra- and extracellular enzymes which inactivate many compounds that attempt passage through the BBB. Finally, the capillary endothelium contains a large number of efflux transporters. Thus, the main routes for transport across the BBB are: 1) the paracellular aqueous pathway, which is restricted by the tight junctions; 2) the transcellular lipophilic pathway; 3) substrate-specific transport proteins; 4) receptormediated transcytosis; and 5) adsorptive-mediated transcytosis [3-6]. Due to the specificity and restrictive nature of the BBB, only lipophilic drugs with a molecular weight $<500$ Daltons cross the BBB in pharmacologically significant amounts; the vast majority of traditional candidate drugs do not meet this requirement [7].

In an attempt to overcome these limitations, nanocarriers have been investigated as drug delivery vehicles for CNS therapeutics [8-13]. The term nanocarriers applies to a wide variety of drug delivery vehicles including dendrimers, micelles, liposomes, nanoscale ceramics, and polymer nanoparticles. These nanocarriers have been proposed as a means to improve delivery efficiency, reduce off-target effects, improve drug kinetics, and allow delivery of a chemically diverse range of therapeutic agents. For the purposes of CNS delivery, it should be possible to optimize nanocarriers for either systemic (through the BBB) or local (behind the BBB) delivery. For systemically-delivered nanoparticles, the particles must be optimized to cross the BBB by exploiting receptor-mediated and adsorptive-mediated transcytosis pathways (Figure 1a) [3, 8]. In contrast, local delivery of nanoparticles completely bypasses the BBB and relies on convection-enhanced delivery (CED) to achieve clinically-relevant volumes of distribution (Figure 1b) [13, 14]. In this case, the delivery systems must be optimized for delivery by CED and transport through the brain interstitium. In both cases, the rate of agent release from the nanocarrier can also be optimized for each clinical application. This review summarizes the development of a particular class of nanocarriers-polymeric nanoparticles-which are promising vehicles for both systemic and local drug delivery to the CNS.

\section{Polymeric Nanoparticles}

Nanocarriers are colloidal systems that range in size from 1 to $300 \mathrm{~nm}$ and contain a therapeutic agent. They can be fabricated from a variety of substances, including polymers, lipids, ceramics, and carbon nanotubes. In contrast to other compositions, polymer materials have the best combination of characteristics (Figure 2): they are stable and allow high loading of many agents, they provide control over drug release kinetics, they can be readily modified to display a variety of surface-attached ligands, and many polymers have a long history of safe use in humans [15].

\subsection{Pre-Clinical Studies}

Many natural and synthetic polymers have been used to create nanoparticles for CNS delivery, including polysaccharides, proteins, amino acids, poly(ethylenimines), poly(alkylcyanoacrylates), poly(methylidene malonates), and polyesters. In general, polymer choice is determined by the therapeutic goals of the nanoparticle system. Here, we highlight the major pre-clinical, in vivo studies which have investigated the use of polymer nanoparticles for CNS drug delivery. 
2.11 Systemic Delivery-As stated earlier, systemic delivery of polymeric nanoparticles to the CNS is based largely on their potential for receptor-mediated transcytosis and adsorptive-mediated transcytosis through the BBB. This process can be enhanced by the addition of cell-penetrating peptides and/or targeting ligands to the nanoparticle surface. In studies to date, the nanoparticle systems described in this section have shown the most promise for bypassing the BBB.

Poly(butylcyanoacrylate) (PBCA) nanoparticles were the first polymer-based nanoparticle system used to deliver drugs to the CNS [16]. In these first studies, PBCA nanoparticles were loaded with dalargin (a compound with opioid activity), coated with polysorbate 80, and delivered intravenously, with the goal of achieving therapeutic drug levels within the CNS. In vivo studies demonstrated that dalargin-loaded PBCA particles had an antinociceptive effect [16]. Follow-up studies, using particles that were radiolabeled for sensitive detection, demonstrated that in the absence of polysorbate 80 coating, there was a significant decrease in the number of PBCA nanoparticles that crossed the BBB [17]. As a result of this and other work, polysorbate 80 (also known as Tween 80 or polyoxyethylene-20 sorbitan monooleate) appears to enhance the CNS penetration of systemically-delivered polymer nanoparticles. Polysorbate 80 , which is a commonly used emulsifier and surfactant, appears to act by a) decreasing nanoparticle clearance by the reticuloendothelial system (RES), b) interacting with BBB endothelial receptors in a manner similar to low density lipoproteins, and c) possibly modulating tight junctions and efflux transporters [18-20].

Polyesters such as poly(lactic acid) (PLA) and poly(glycolic acid) (PGA), and their copolymer poly(lactic-co-glycolic acid) (PLGA) have also been widely studied because of their history of safe use in medicine. Systemically-administered PLA nanoparticles, loaded with breviscapine (a flavonoid), have been shown to penetrate the BBB in a size-dependent manner, with larger particles $(\sim 300 \mathrm{~nm})$ delivering more drug to the brain than smaller ones $(\sim 200 \mathrm{~nm})$ [21]. In other work, drug-loaded PLA nanoparticles that had trans-activating transcriptor (TAT) peptide attached to the particle surface leads to increased nanoparticle transport across the BBB via bypass of efflux transporters [22]. Similar to the initial PBCA studies, surface coating of PLGA nanoparticles with polysorbate 80 and poloaxmer 188 has also been proven to improve CNS penetration [23]. Recent studies with paclitaxel-loaded PLGA nanoparticles demonstrates that surface modification with glutathione may also improve BBB bypass [24].

Several types of polymer nanoparticles with high density positive charge have been reported to cross the BBB. Chitosan is a naturally occurring biodegradable, biocompatible polysaccharide which has the ability to efficiently form nanoparticles [25]. Early work demonstrated that intranasal delivery of estradiol-loaded chitosan nanoparticles leads to significant amounts of estradiol within the CNS [26]. More recent work has demonstrated that chitosan nanoparticles can be used to deliver peptides (amyloid-beta subfragments), dopamine, and caspase inhibitors to the CNS following systemic administration [27-29]. Additionally, chitosan particles can be surface modified to display a variety of ligands for BBB bypass, including transferrin receptor antibodies [30]. Of particular interest for future efforts, at $\mathrm{pH}<6$, the amino groups of chitosan are protonated and the polymer is positively charged, making it an attractive for nucleic acid delivery [25].

Similar to chitosan, poly(ethylenimines) (PEIs) are cationic polymers that are well-suited for nucleic acid delivery. Recently, systemically-delivered, disulfide-linked PEI nanoparticles (surface modified with peptides derived from a rabies virus glycoprotein that is known to facilitate BBB passage [31]) have been shown to deliver microRNAs to the CNS [32]. 
Although there were size-related inefficiencies, the addition of mannitol assisted in bloodbrain barrier disruption and improved delivery.

Our review of the literature - and our own experience—suggests that, in the absence of surface modification, polymeric nanoparticles have limited capacity to cross the BBB. Perhaps future research efforts will succeed in finding strategies to enhance particle transit through the BBB. Surface modification with surfactants or ligands can enhance receptormediated endocytosis, while surface display of positive charges can enhance adsorptivemediated endocytosis. Transient physical disruption of the BBB via intravenous administration of hyperosmolar agents or deposition of ultrasound energy also shows some promise, although the risk of side effects of physical disruption is high. A further problem with evaluating BBB penetration is the difficulty in quantifying BBB transit, and the risk of artifacts with most experimental techniques that employed. We believe that radiolabeling techniques are best-suited to quantify the delivery efficiency of systemically administered polymeric nanoparticles. Still, these techniques will need to be carefully employed to demonstrate that systemically delivered nanoparticles can accumulate to therapeutic amounts in the brain.

2.12 Local Delivery-Local delivery of therapeutic agents in the CNS has a long history of clinical success [13, 33-36]. Local delivery of therapeutics bypasses the BBB altogether. Initial work in this field focused on the implantation of drug-loaded biodegradable polymer wafers (Gliadel ${ }^{\circledR}$ ), which are able to release drugs in a controlled fashion over a prolonged period of time and resulted in modest improvements in patient survival $[37,38]$. Although capable of delivering large doses of drug to the site of tumor resection over a sustained period, the drug released from the implants had limited penetration beyond the tumor margin, which could limit overall efficacy [39]. CED of drug-loaded polymer nanoparticles offers a solution to this problem. In CED, an external pressure gradient is established, typically through a syringe pump, and agents are infused continuously into the brain tissue via bulk fluid flow [40]. This can lead to distribution of therapeutics over large volumes in the brain. Although the investigation of nanoparticles for local CNS delivery has, thus far, focused largely on liposomal preparations [41-43], it is now possible to design polymer nanoparticles that can be delivered by CED $[44,45]$.

The first particulate systems that were used for direct drug delivery to the brain were microspheres. Polymer microspheres have been fabricated from a variety of materials for the purposes of local delivery including PLGA, poly(methylidene malonate) (PMM), poly(epsilon-caprolactone), and chitosan. These systems have been used to deliver a range of therapeutics, including cyclosporine, paclitaxel, imatinib, mitoxantrone, phenytoin, and nerve growth factor [46-51]. One advantage of microparticles, over earlier implant systems such as Gliadel ${ }^{\circledR}$, is that the particles can be introduced without surgery. But, because particles larger than 1 micron in diameter do not move readily through the BBB or the brain interstitium [52, 53], it is difficult for microparticles to distribute through large volumes of brain tissue.

In contrast, when nanoparticles are used to deliver agents instead of microparticles, particularly nanoparticles that are less than $100 \mathrm{~nm}$ in diameter, CED can be used to transport the particles over clinically relevant volumes of distribution [44, 54]. For most intracranial applications, this implies achieving a volume of distribution that is $>3$ times the volume of infused therapeutic agent [54-56]. A recent study showed, for the first time, that drug-loaded polymer nanoparticles can be used effectively to treat disease in the brain when delivered via CED. Specifically, camptothecin-loaded PLGA nanoparticles were delivered locally and demonstrated to be effective for treatment of an intracranial tumor model [45]. 
Further optimization of polymer nanoparticle design, by control of nanoparticle size, charge, and surface coatings, promise to make this delivery strategy even more effective [57].

CED of polymeric nanoparticles is an attractive therapeutic strategy. Large clinical trials have already demonstrated the feasibility of intracranial CED with free drug [35]. In contrast to systemic delivery, CED has limited off target effects and no significant systemic toxicity. Moreover, with the currently available polymer nanoparticle systems, CED allows for delivery of larger amounts of therapeutic agents than systemic nanoparticle administration. In our experience, CED of polymeric nanoparticles can be achieved in large animal models, to volumes which are relevant for human clinical use. Despite this promise, intracranial $\mathrm{CED}$ is an invasive neurosurgical procedure, which may be impractical for some patients.

\subsection{Features of an Ideal Polymer Nanoparticle Delivery System}

Based on the existing data, the key features of an ideal nanoparticle system can be deduced. In general, for optimal CNS delivery, a nanoparticle should be: 1) scalable and costeffective, 2) biocompatible/biodegradable, 3) non-toxic, 4) non-immunogenic, 5) $<100 \mathrm{~nm}$ in diameter, and 6) amenable to robust surface modification. For systemic delivery, nanoparticles should also: 1) be stable in blood, 2) avoid the RES, and 3) have prolonged circulation times. For local delivery, nanoparticles should also: 1) be neutral or negatively charged and 2) be infused in a slightly viscous, slightly hyperosmolar solution.

\section{Current Clinical Applications}

Although several clinical trials have investigated the role of nanoliposomal vehicles for CNS drug delivery, there have not yet been similar studies for polymeric nanoparticles [58]. Currently, there are two polymeric nanoparticle drug delivery systems on the market for non-CNS applications: 1) Abraxane ${ }^{\circledR}$, an albumin-based nanoparticle loaded with paclitaxel and used in the treatment for breast cancer and 2) Abdoscan ${ }^{\circledR}$, an iron oxide and dextranbased nanoparticle used for diagnostic imaging of the liver and spleen.

\section{Conclusions}

Polymeric nanoparticles have significant potential for drug delivery to the CNS. Over the past 40 years, this technology has undergone rapid expansion and is now poised for clinical translation. With the array of polymers and surface modification techniques currently available, polymeric nanoparticles have the potential to deliver not only traditional small molecule drugs, but also nucleic acids [59], proteins [60], and diagnostic agents [61]. Moreover, in comparison to other nanocarrier systems, polymeric nanoparticles are generally safer and more stable; they can also be easier to prepare and offer better control over agent release. As this technology moves forward, some of the major challenges to clinical translation will be the ability to scale-up this system in a cost-effective manner. Nonetheless, given the aging population and increasing prevalence of neurological disorders, the demand for improved CNS therapeutics is only going to increase with time. In particular, the application of polymeric nanoparticles to CNS malignancies, neurodegenerative disorders, and ischemic disease will be of interest.

\section{References}

1. World Health Organization. Neurological disorders : public health challenges. Geneva: World Health Organization; 2006.

2. Abbott A. Dementia: a problem for our age. Nature. 2011; 475:S2-S4. [PubMed: 21760579]

3. Yang H. Nanoparticle-mediated brain-specific drug delivery, imaging, and diagnosis. Pharmaceutical research. 2010; 27:1759-1771. [PubMed: 20593303] 
*4. Abbott NJ, Ronnback L, Hansson E. Astrocyte-endothelial interactions at the blood-brain barrier, Nature reviews. Neuroscience. 2006; 7:41-53. [PubMed: 16371949]

5. Wilhelm I, Fazakas C, Krizbai IA. In vitro models of the blood-brain barrier. Acta neurobiologiae experimentalis. 2011; 71:113-128. [PubMed: 21499332]

6. Bhaskar S, Tian F, Stoeger T, Kreyling W, de la Fuente JM, Grazu V, Borm P, Estrada G, Ntziachristos V, Razansky D. Multifunctional Nanocarriers for diagnostics, drug delivery and targeted treatment across blood-brain barrier: perspectives on tracking and neuroimaging. Particle and fibre toxicology. 2010; 7:3. [PubMed: 20199661]

7. Pardridge WM. Crossing the blood-brain barrier: are we getting it right? Drug discovery today. 2001; 6:1-2. [PubMed: 11165157]

*8. Barbu E, Molnar E, Tsibouklis J, Gorecki DC. The potential for nanoparticle-based drug delivery to the brain: overcoming the blood-brain barrier. Expert opinion on drug delivery. 2009; 6:553565. [PubMed: 19435406]

9. Blanco E, Hsiao A, Mann AP, Landry MG, Meric-Bernstam F, Ferrari M. Nanomedicine in cancer therapy: innovative trends and prospects. Cancer science. 2011; 102:1247-1252. [PubMed: 21447010]

10. Koo YE, Reddy GR, Bhojani M, Schneider R, Philbert MA, Rehemtulla A, Ross BD, Kopelman R. Brain cancer diagnosis and therapy with nanoplatforms. Advanced drug delivery reviews. 2006; 58:1556-1577. [PubMed: 17107738]

11. Kreuter J. Nanoparticulate systems for brain delivery of drugs. Advanced drug delivery reviews. 2001; 47:65-81. [PubMed: 11251246]

12. Lockman PR, Mumper RJ, Khan MA, Allen DD. Nanoparticle technology for drug delivery across the blood-brain barrier. Drug development and industrial pharmacy. 2002; 28:1-13. [PubMed: 11858519]

13. Sawyer AJ, Piepmeier JM, Saltzman WM. New methods for direct delivery of chemotherapy for treating brain tumors. The Yale journal of biology and medicine. 2006; 79:141-152. [PubMed: 17940624]

*14. Allard E, Passirani C, Benoit JP. Convection-enhanced delivery of nanocarriers for the treatment of brain tumors. Biomaterials. 2009; 30:2302-2318. [PubMed: 19168213]

15. Saltzman, WM. Drug Delivery: Engineering principles for drug therapy. New York: Oxford University Press; 2001.

**16. Kreuter J, Alyautdin RN, Kharkevich DA, Ivanov AA. Passage of peptides through the bloodbrain barrier with colloidal polymer particles (nanoparticles). Brain research. 1995; 674:171-174. [PubMed: 7773690]

17. Schroeder U, Schroeder H, Sabel BA. Body distribution of 3H-labelled dalargin bound to poly(butyl cyanoacrylate) nanoparticles after i.v. injections to mice. Life sciences. 2000; 66:495502. [PubMed: 10794066]

18. Kreuter J. Influence of the surface properties on nanoparticle-mediated transport of drugs to the brain. Journal of nanoscience and nanotechnology. 2004; 4:484-488. [PubMed: 15503433]

*19. Kreuter J, Ramge P, Petrov V, Hamm S, Gelperina SE, Engelhardt B, Alyautdin R, von Briesen H, Begley DJ. Direct evidence that polysorbate-80-coated poly(butylcyanoacrylate) nanoparticles deliver drugs to the CNS via specific mechanisms requiring prior binding of drug to the nanoparticles. Pharmaceutical research. 2003; 20:409-416. [PubMed: 12669961]

20. Kreuter J, Shamenkov D, Petrov V, Ramge P, Cychutek K, Koch-Brandt C, Alyautdin R. Apolipoprotein-mediated transport of nanoparticle-bound drugs across the blood-brain barrier. Journal of drug targeting. 2002; 10:317-325. [PubMed: 12164380]

21. Liu M, Li H, Luo G, Liu Q, Wang Y. Pharmacokinetics and biodistribution of surface modification polymeric nanoparticles. Archives of pharmacal research. 2008; 31:547-554. [PubMed: 18449515]

22. Rao KS, Reddy MK, Horning JL, Labhasetwar V. TAT-conjugated nanoparticles for the CNS delivery of anti-HIV drugs. Biomaterials. 2008; 29:4429-4438. [PubMed: 18760470]

23. Kulkarni SA, Feng SS. Effects of surface modification on delivery efficiency of biodegradable nanoparticles across the blood-brain barrier. Nanomedicine (Lond). 2011; 6:377-394. [PubMed: 21385139] 
24. Geldenhuys W, Mbimba T, Bui T, Harrison K, Sutariya V. Brain-targeted delivery of paclitaxel using glutathione-coated nanoparticles for brain cancers. Journal of drug targeting. 2011

25. Nagpal K, Singh SK, Mishra DN. Chitosan nanoparticles: a promising system in novel drug delivery. Chemical \& pharmaceutical bulletin. 2010; 58:1423-1430.

26. Wang X, Chi N, Tang X. Preparation of estradiol chitosan nanoparticles for improving nasal absorption and brain targeting. European journal of pharmaceutics and biopharmaceutics : official journal of Arbeitsgemeinschaft fur Pharmazeutische Verfahrenstechnik e.V. 2008; 70:735-740. [PubMed: 18684400]

27. Songjiang Z, Lixiang W. Amyloid-beta associated with chitosan nano-carrier has favorable immunogenicity and permeates the BBB. AAPS PharmSciTech. 2009; 10:900-905. [PubMed: 19609682]

28. Trapani A, De Giglio E, Cafagna D, Denora N, Agrimi G, Cassano T, Gaetani S, Cuomo V, Trapani G. Characterization and evaluation of chitosan nanoparticles for dopamine brain delivery. International journal of pharmaceutics. 2011

*29. Karatas H, Aktas Y, Gursoy-Ozdemir Y, Bodur E, Yemisci M, Caban S, Vural A, Pinarbasli O, Capan Y, Fernandez-Megia E, Novoa-Carballal R, Riguera R, Andrieux K, Couvreur P, Dalkara T. A nanomedicine transports a peptide caspase- 3 inhibitor across the blood-brain barrier and provides neuroprotection. The Journal of neuroscience : the official journal of the Society for Neuroscience. 2009; 29:13761-13769. [PubMed: 19889988]

30. Aktas Y, Yemisci M, Andrieux K, Gursoy RN, Alonso MJ, Fernandez-Megia E, Novoa-Carballal R, Quinoa E, Riguera R, Sargon MF, Celik HH, Demir AS, Hincal AA, Dalkara T, Capan Y, Couvreur P. Development and brain delivery of chitosan-PEG nanoparticles functionalized with the monoclonal antibody OX26. Bioconjugate chemistry. 2005; 16:1503-1511. [PubMed: $16287248]$

31. Kumar P, Wu H, McBride JL, Jung KE, Hee Kim M, Davidson BL, Kyung Lee S, Shankar P, Manjunath N. Transvascular delivery of small interfering RNA to the central nervous system. Nature. 2007; 448:39-43. [PubMed: 17572664]

32. Hwang do W, Son S, Jang J, Youn H, Lee S, Lee D, Lee YS, Jeong JM, Kim WJ, Lee DS. A braintargeted rabies virus glycoprotein-disulfide linked PEI nanocarrier for delivery of neurogenic microRNA. Biomaterials. 2011; 32:4968-4975. [PubMed: 21489620]

**33. Brem H, Piantadosi S, Burger PC, Walker M, Selker R, Vick NA, Black K, Sisti M, Brem S, Mohr G, Muller P, Morawetz R, Schold SC. P.-B.T.T. Group. Placebo-controlled trial of safety and efficacy of intraoperative controlled delivery by biodegradable polymers of chemotherapy for recurrent gliomas. Lancet. 1995; 345:1008-1012. [PubMed: 7723496]

34. Jacobs A, Voges J, Reszka R, Lercher M, Gossmann A, Kracht L, Kaestle C, Wagner R, Wienhard K, Heiss WD. Positron-emission tomography of vector-mediated gene expression in gene therapy for gliomas. Lancet. 2001; 358:727-729. [PubMed: 11551583]

35. Kunwar S, Chang S, Westphal M, Vogelbaum M, Sampson J, Barnett G, Shaffrey M, Ram Z, Piepmeier J, Prados M, Croteau D, Pedain C, Leland P, Husain SR, Joshi BH, Puri RK. Phase III randomized trial of CED of IL13-PE38QQR vs Gliadel wafers for recurrent glioblastoma. Neurooncology. 2010; 12:871-881.

36. Sampson JH, Akabani G, Archer GE, Berger MS, Coleman RE, Friedman AH, Friedman HS, Greer K, Herndon JE 2nd, Kunwar S, McLendon RE, Paolino A, Petry NA, Provenzale JM, Reardon DA, Wong TZ, Zalutsky MR, Pastan I, Bigner DD. Intracerebral infusion of an EGFRtargeted toxin in recurrent malignant brain tumors. Neurooncology. 2008; 10:320-329.

37. Brem H, Mahaley MS Jr, Vick NA, Black KL, Schold SC Jr, Burger PC, Friedman AH, Ciric IS, Eller TW, Cozzens JW, et al. Interstitial chemotherapy with drug polymer implants for the treatment of recurrent gliomas. Journal of neurosurgery. 1991; 74:441-446. [PubMed: 1993909]

38. Fung LK, Saltzman WM. Polymeric implants for cancer chemotherapy. Advanced drug delivery reviews. 1997

*39. Fung LK, Shin M, Tyler B, Brem H, Saltzman WM. Chemotherapeutic drugs released from polymers: distribution of 1,3-bis(2-chloroethyl)-1-nitrosourea in the rat brain. Pharmaceutical research. 1996; 13:671-682. [PubMed: 8860421] 
**40. Bobo RH, Laske DW, Akbasak A, Morrison PF, Dedrick RL, Oldfield EH. Convectionenhanced delivery of macromolecules in the brain. Proceedings of the National Academy of Sciences of the United States of America. 1994; 91:2076-2080. [PubMed: 8134351]

41. Mamot C, Nguyen JB, Pourdehnad M, Hadaczek P, Saito R, Bringas JR, Drummond DC, Hong K, Kirpotin DB, McKnight T, Berger MS, Park JW, Bankiewicz KS. Extensive distribution of liposomes in rodent brains and brain tumors following convection-enhanced delivery. Journal of neuro-oncology. 2004; 68:1-9. [PubMed: 15174514]

42. Noble CO, Krauze MT, Drummond DC, Yamashita Y, Saito R, Berger MS, Kirpotin DB, Bankiewicz KS, Park JW. Novel nanoliposomal CPT-11 infused by convection-enhanced delivery in intracranial tumors: pharmacology and efficacy. Cancer research. 2006; 66:2801-2806. [PubMed: 16510602]

43. Saito R, Krauze MT, Noble CO, Drummond DC, Kirpotin DB, Berger MS, Park JW, Bankiewicz KS. Convection-enhanced delivery of Ls-TPT enables an effective, continuous, low-dose chemotherapy against malignant glioma xenograft model. Neuro-oncology. 2006; 8:205-214. [PubMed: 16723630]

44. Neeves KB, Sawyer AJ, Foley CP, Saltzman WM, Olbricht WL. Dilation and degradation of the brain extracellular matrix enhances penetration of infused polymer nanoparticles. Brain research. 2007; 1180:121-132. [PubMed: 17920047]

**45. Sawyer AJ, Saucier-Sawyer JK, Booth CJ, Liu J, Patel T, Piepmeier JM, Saltzman WM. Convection-enhanced delivery of camptothecin-loaded polymer nanoparticles for treatment of intracranial tumors. Drug delivery and translational research. 2011; 1:34-42. [PubMed: 21691426]

46. Benny O, Menon LG, Ariel G, Goren E, Kim SK, Stewman C, Black PM, Carroll RS, Machluf M. Local delivery of poly lactic-co-glycolic acid microspheres containing imatinib mesylate inhibits intracranial xenograft glioma growth. Clinical cancer research : an official journal of the American Association for Cancer Research. 2009; 15:1222-1231. [PubMed: 19190128]

47. Fournier E, Passirani C, Montero-Menei C, Colin N, Breton P, Sagodira S, Menei P, Benoit JP. Therapeutic effectiveness of novel 5-fluorouracil-loaded poly(methylidene malonate 2.1.2)-based microspheres on F98 glioma-bearing rats. Cancer. 2003; 97:2822-2829. [PubMed: 12767096]

48. Li Z, Li Q, Simon S, Guven N, Borges K, Youan BB. Formulation of spray-dried phenytoin loaded poly(epsilon-caprolactone) microcarrier intended for brain delivery to treat epilepsy. Journal of pharmaceutical sciences. 2007; 96:1018-1030. [PubMed: 17455322]

49. Turkoglu OF, Eroglu H, Gurcan O, Bodur E, Sargon MF, Oner L, Beskonakli E. Local administration of chitosan microspheres after traumatic brain injury in rats: a new challenge for cyclosporine--a delivery. British journal of neurosurgery. 2010; 24:578-583. [PubMed: 20868245]

50. Yemisci M, Bozdag S, Cetin M, Soylemezoglu F, Capan Y, Dalkara T, Vural I. Treatment of malignant gliomas with mitoxantrone-loaded poly (lactide-co-glycolide) microspheres. Neurosurgery. 2006; 59:1296, 1302. discussion 1302-1293. [PubMed: 17277693]

51. Saltzman WM, Mak MW, Mahoney MJ, Duenas ET, Cleland JL. Intracranial delivery of recombinant nerve growth factor: release kinetics and protein distribution for three delivery systems. Pharmaceutical research. 1999; 16:232-240. [PubMed: 10100308]

52. Hobbs SK, Monsky WL, Yuan F, Roberts WG, Griffith L, Torchilin VP, Jain RK. Regulation of transport pathways in tumor vessels: role of tumor type and microenvironment. Proceedings of the National Academy of Sciences of the United States of America. 1998; 95:4607-4612. [PubMed: 9539785]

**53. Thorne RG, Nicholson C. In vivo diffusion analysis with quantum dots and dextrans predicts the width of brain extracellular space. Proceedings of the National Academy of Sciences of the United States of America. 2006; 103:5567-5572. [PubMed: 16567637]

54. Chen MY, Hoffer A, Morrison PF, Hamilton JF, Hughes J, Schlageter KS, Lee J, Kelly BR, Oldfield EH. Surface properties, more than size, limiting convective distribution of virus-sized particles and viruses in the central nervous system. Journal of neurosurgery. 2005; 103:311-319. [PubMed: 16175862]

55. Chen MY, Lonser RR, Morrison PF, Governale LS, Oldfield EH. Variables affecting convectionenhanced delivery to the striatum: a systematic examination of rate of infusion, cannula size, 
infusate concentration, and tissue-cannula sealing time. Journal of neurosurgery. 1999; 90:315320. [PubMed: 9950503]

56. Levin VA, Fenstermacher JD, Patlak CS. Sucrose and inulin space measurements of cerebral cortex in four mammalian species. The American journal of physiology. 1970; 219:1528-1533. [PubMed: 4990676]

57. Patel T, Zhou J, Piepmeier J, Saltzman WM. Ultrasmall polymeric nanoparticles improve distribution volume during convection-enhnaced delivery. Neuro-oncology. 2010; 12(Supplement 4):91.

58. Service RF. Nanotechnology. Nanoparticle Trojan horses gallop from the lab into the clinic. Science. 2010; 330:314-315. [PubMed: 20947742]

59. Woodrow KA, Cu Y, Booth CJ, Saucier-Sawyer JK, Wood MJ, Saltzman WM. Intravaginal gene silencing using biodegradable polymer nanoparticles densely loaded with small-interfering RNA. Nature Materials. 2009; 8:526-533.

60. Demento SL, Eisenbart SC, Foellmer HG, Platt C, Caplan MJ, Saltzman WM, Mellman I, Ledizet M, Fikrig E, Flavell RA, Fahmy TM. Inflammasome-activating nanoparticles as modular systems for optimizing vaccine efficacy. Vaccine. 2009; 27:3013-3021. [PubMed: 19428913]

61. Fahmy TM, Fong PM, Park J, Constable T, Saltzman WM. Nanosystems for simultaneous imaging and drug delivery to T cells. The AAPS Journal. 2007; 9:E171-E179. [PubMed: 17614359]

62. Zhou J, Patel TR, Fu M, Bertram JP, Saltzman WM. Octa-functional PLGA nanoparticles for targeted and efficient siRNA delivery to tumors. Biomaterials. 2011; 33:583-591. [PubMed: 22014944] 
a

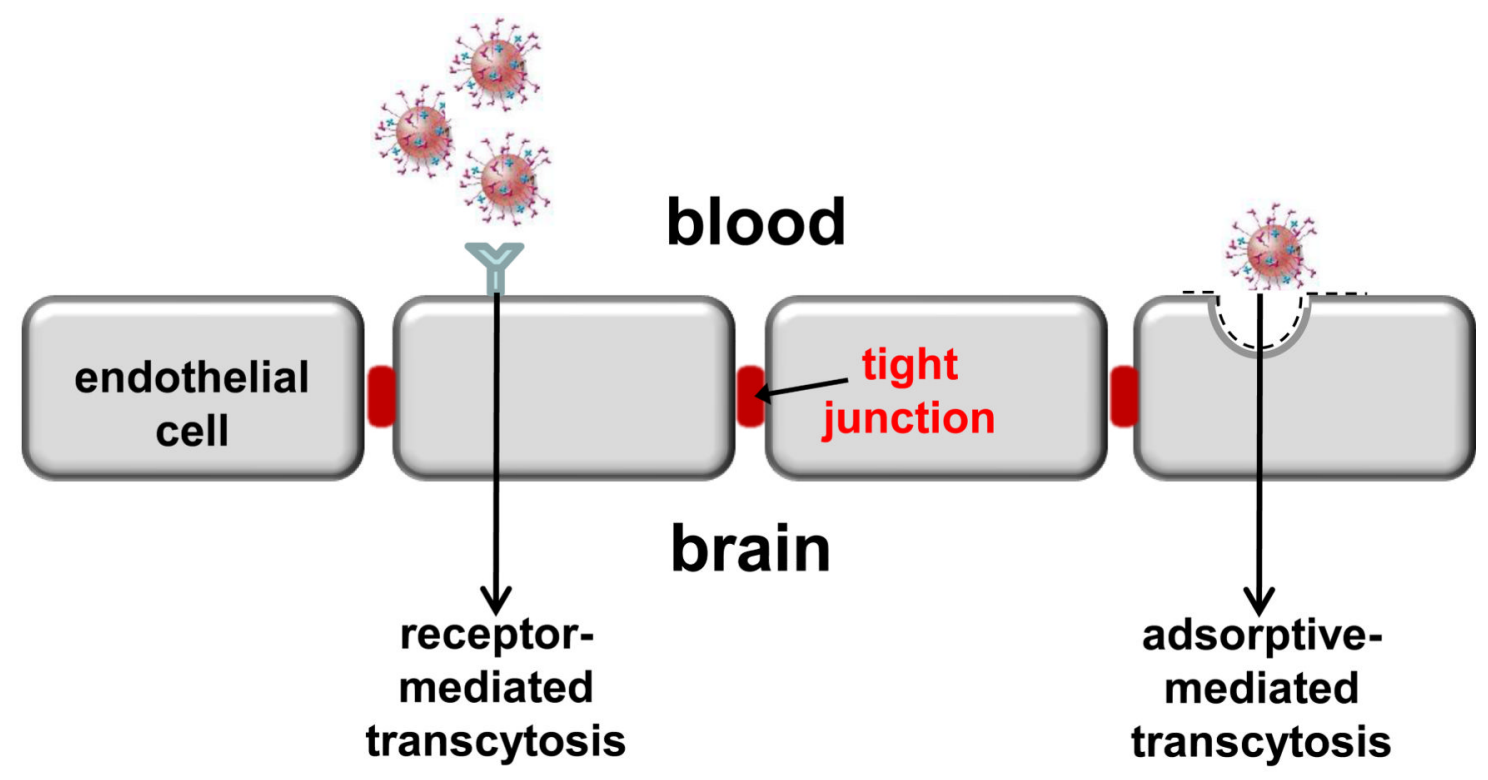

b
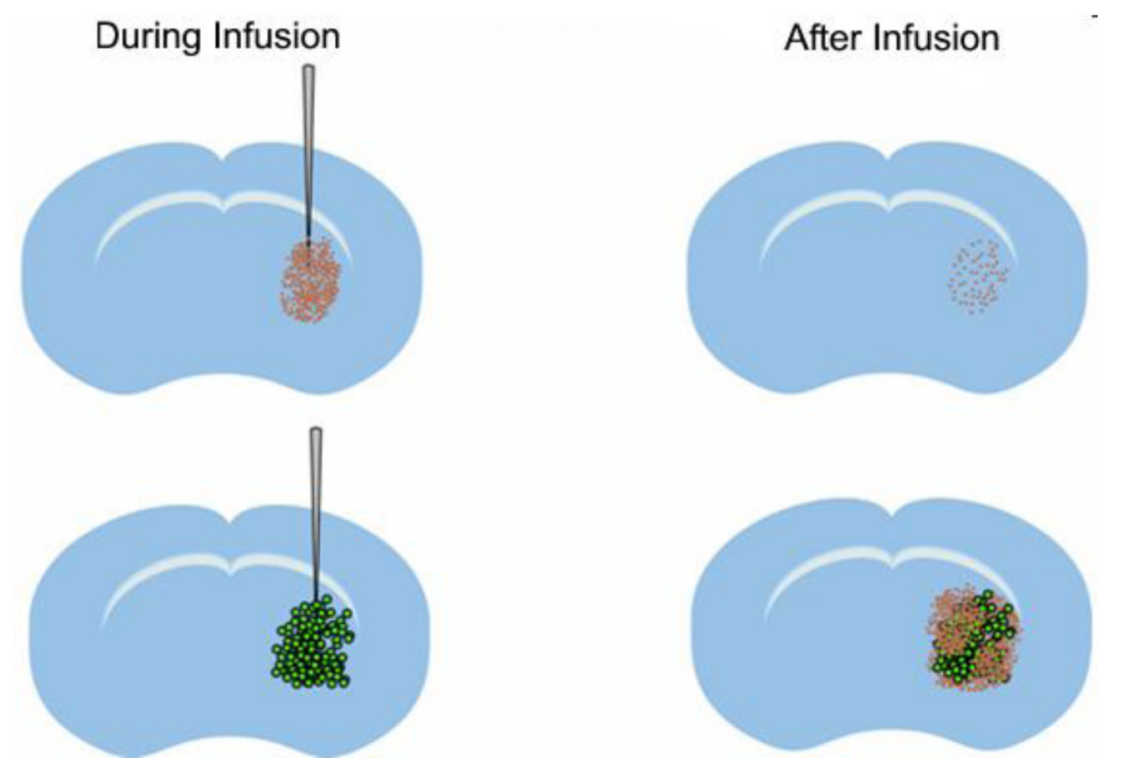

Figure 1.

a) Systemically-delivered nanoparticles cross the BBB via either receptor-mediated transcytosis, which requires the presence of specific ligands on the nanoparticle surface, or adsorptive-mediated transcytosis, which utilizes charge-based interactions. b) Locallydelivered nanoparticles bypass the BBB altogether and rely on CED to achieve adequate distribution. With CED of free drugs (top row), there is adequate initial distribution, but the drugs disappear quickly after the infusion stops. However, with CED of nanoparticles (bottom row), widely-distributed nanoparticles provide long-lasting drug release. 


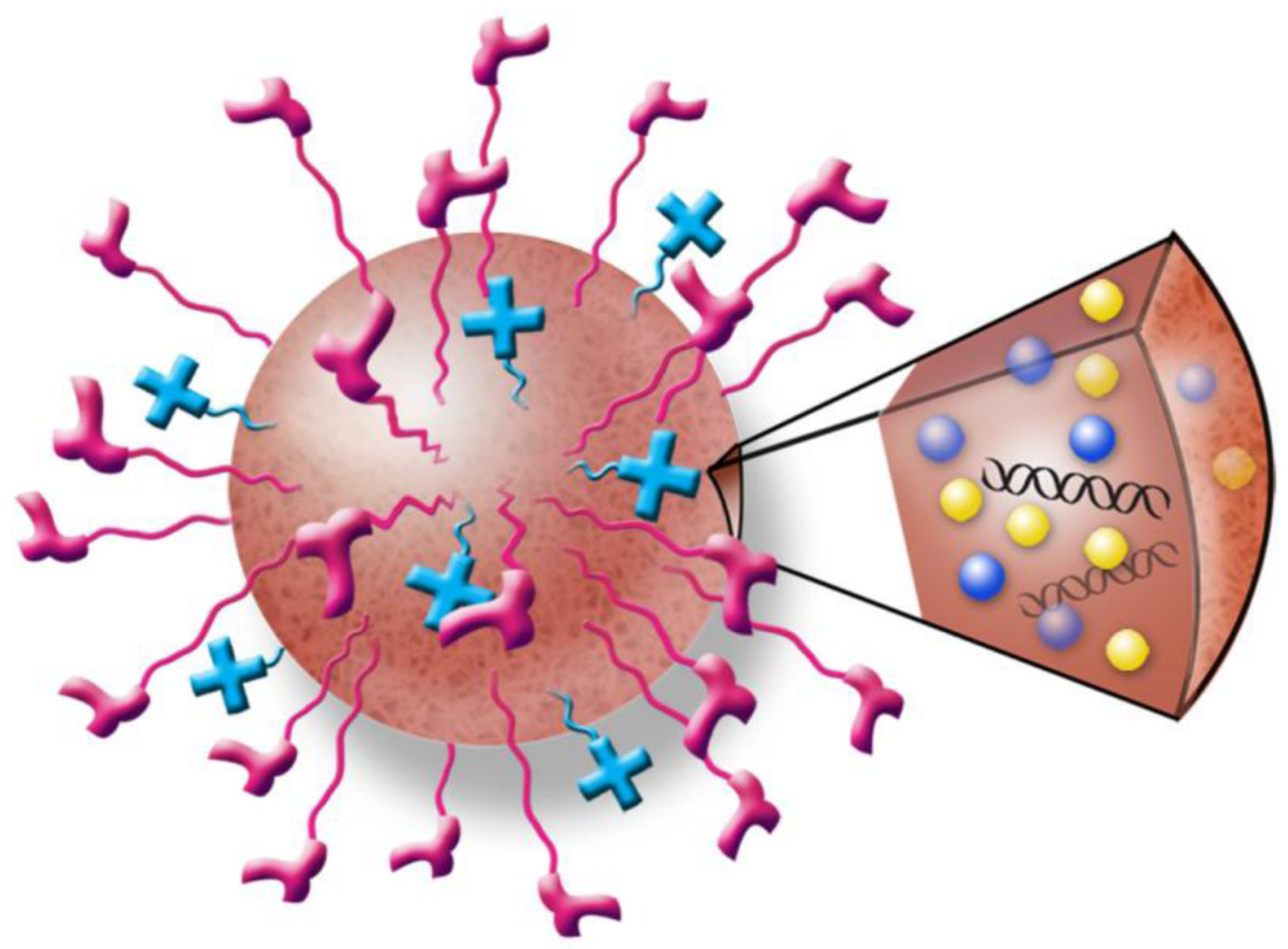

polymer
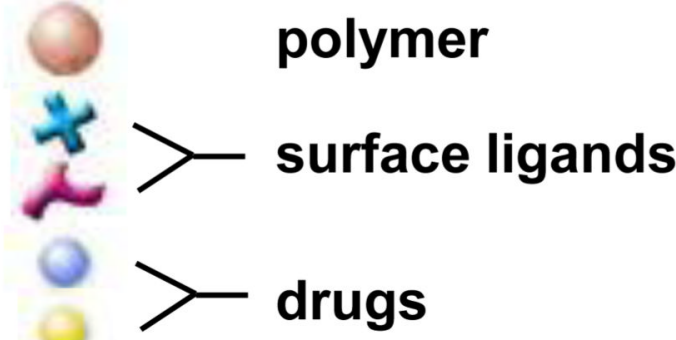

sacoos

\section{nucleic acids}

Figure 2.

Schematic of a functionalized polymer nanoparticle. This type of vehicle can be readily customized to suit the needs of a particular drug delivery application. In particular, the polymer, surface ligands, and encapsulated therapeutic agents can all be modified. This flexibility allows for control over release kinetics, cell targeting, and treatment strategy, respectively. Reproduced, with permission from ref. 62. 